\title{
Peningkatan Pengetahuan tentang Pembangunan Berkelanjutan Menggunakan Media Cerita Bergambar di Tingkat Sekolah Dasar
}

\author{
Yoga Suharman ${ }^{1}$, Sadewa Purba Sejati ${ }^{2}$, Dimas Adi Pratama ${ }^{3}$ \\ ${ }^{1}$ Program Studi S1-Hubungan Internasional, Fakultas Ekonomi dan Sosial, Universitas AMIKOM \\ Yogyakarta. \\ ${ }^{2}$ Program Studi S1-Geografi, Fakultas Sains dan Teknologi, Universitas AMIKOM Yogyakarta. \\ ${ }^{3}$ Program Studi S1-Hubungan Internasional, Fakultas Ekonomi dan Sosial, Universitas AMIKOM \\ Yogyakarta \\ *e-mail: yoga.shrmn@amikom.ac.id ${ }^{1}$,sadewa@amikom.ac.id², dimas.pratama@students.amikom.ac.id ${ }^{3}$
}

\begin{abstract}
This community service entitled Enhancement Knowledge of Sustainable Development with Pictorial Story at Elementary School was carried out to strengthen the knowledge capacity and attitude related to groundwater resources in Bronggang Baru, Cangkringan District, Sleman, Yogyakarta. The method of implementing community service was conducted by three steps, consist of 1) literature review and problem analysis, 2) interviews and analysis of partner needs, and 3) developing and delivering the media of pictorial story about sustainable development and its relation to groundwater. The result of the activity shows that $80 \%$ from the 25 of pupils who attended knew more about the insights of sustainable development, particularly on geographical conditions and water resources of local area.
\end{abstract}

Keywords: Sustainable, Development, Environment; Groundwater; Elementary School.

\begin{abstract}
Abstrak
Kegiatan pengabdian masyarakat yang berjudul Peningkatkan Pengetahuan tentang Pembangunan Berkelanjutan melalui Cerita Bergambar pada Tingkat Sekolah Dasar dilaksanakan dengan tujuan untuk memperkuat kapasitas pengetahuan dan perilaku siswa dan siswi yang terkait dengan kondisi geografis dan sumber daya air tanah Bronggang Baru, Cangkringan District, Sleman, Yogyakarta. Metode pelaksanaan kegiatan ini ditempuh melalui tiga tahap, meliputi, 1) kajian literatur tentang kondisi geografis wilayah setempat dan analisis masalah, 2) analisis dan wawancara kebutuhan mitra, dan )3) mengembangkan dan menyajikan media cerita bergambar tentang pembangunan berkelanjutan dan hubungannnya dengan airtanah. Hasil kegiatan ini menunjukkan bahwa 80\% dari total 25 siswa yang mengikuti kegiatan menjadi lebih mengetahui tentang pembangunan berkelanjutan, khususnya terkait dengan kondisi geografis dan sumber daya air pada wilayah setempat.
\end{abstract}

Kata Kunci: Pembangunan, Berkelanjutan, Lingkungan, Airtanah, Sekolah Dasar.

\section{PENDAHULUAN}

Pada tahun 2015 yang lalu, agenda millennium development goals telah berakhir. Sebagai kelanjutannya, PBB memformulasi ulang agenda tersebut menjadi pembangunan berkelanjutan (sustainable development goals) yang ditargetkan dapat tercapai pada tahun 2030. Beberapa diantara tujuan dari pembangunan berkelanjutan adalah meminimalisir resiko jangka panjang pertumbuhan ekonomi dan memelihara akses kesediaan air bersih (Ferranti, 2018; United Nations, 2016). Selain itu, beberapa resiko lain yang hendak diminimalisir dalam agenda pembangunan berkelanjutan antara lain, kontaminasi bakteri terhadap airtanah yang berdampak terhadap menurunya kesehatan masyarakat yang memanfaatkan airtanah sebagai sumber konsumsi (Wahyuni et al., 2017).

Permasalahan ini memerlukan pendekatan pembangunan yang berorientasi pada keberlanjutan sumber daya air bersih dalam hal tata kelola sekaligus pemanfaatannya baik dalam bentuk reformulasi kebijakan maupun peningkatan literasi masyarakat melalui kegiatan pengabdian masyarakat. Pada dasarnya, pembangunan berkelanjutan yang berkorelasi dengan 
kesediaan air bersih menjadi penting karena sangat erat kaitannya tiga hal, yaitu, kelestarian ekosistem, stabilitas sosial-ekonomi dan kelangsungan hidup masyarakat (Pauw, Gericke, Olsson, \& Berglund, 2015; Springett \& Redclift, 2015).

Berdasarkan tinjauan awal terhadap permasalahan air bersih dalam jangka panjang, maka penting untuk memperkenalkan konsep pembangunan berkelanjutan kepada semua pihak, termasuk memperkenalkan tentang kawasan resapan air hujan ditengah meningkatnya pemukiman penduduk (Apriani \& Haris, 2019) dengan tujuan meningkatkan kesadaran masyarakat Indonesia terhadap lingkungan serta meminimalisir risiko jangka panjang kerusakan lingkungan dan ketersediaan air di wilayah resapan air primer, seperti di daerah sekitar SD Negeri Bronggang Baru, Kecamatan Cangkringan Sleman, Yogyakarta.

Wilayah SD Negeri, Bronggang Baru, Kecamatan Cangkringan, Sleman, Yogyakarta dipilih sebagai mitra pengabdian masyarakat didasari alasan bahwa secara geografis wilayah ini merupakan daerah resapan air primer (Hendrayana \& Vicente, 2013; Setyowati \& Suharini, 2014; Sejati, 2017). Berdasarkan data pengeboran di wilayah tersebut diperoleh hasil bahwa lapisan material tanah Kabupaten Cangkringan mengandung beberapa lapisan material alam yang terdiri dari pasir dengan berbagai ukuran dan ketebalan (Riasasi \& Sejati, 2019; Wardoyo \& Santosa, 2016). Pasir merupakan bahan alami yang memiliki daya serap tinggi (Asdak, 2014; Kodoatie, 2012; Sejati, 2013). Data tersebut dapat dilihat sebagai berikut:

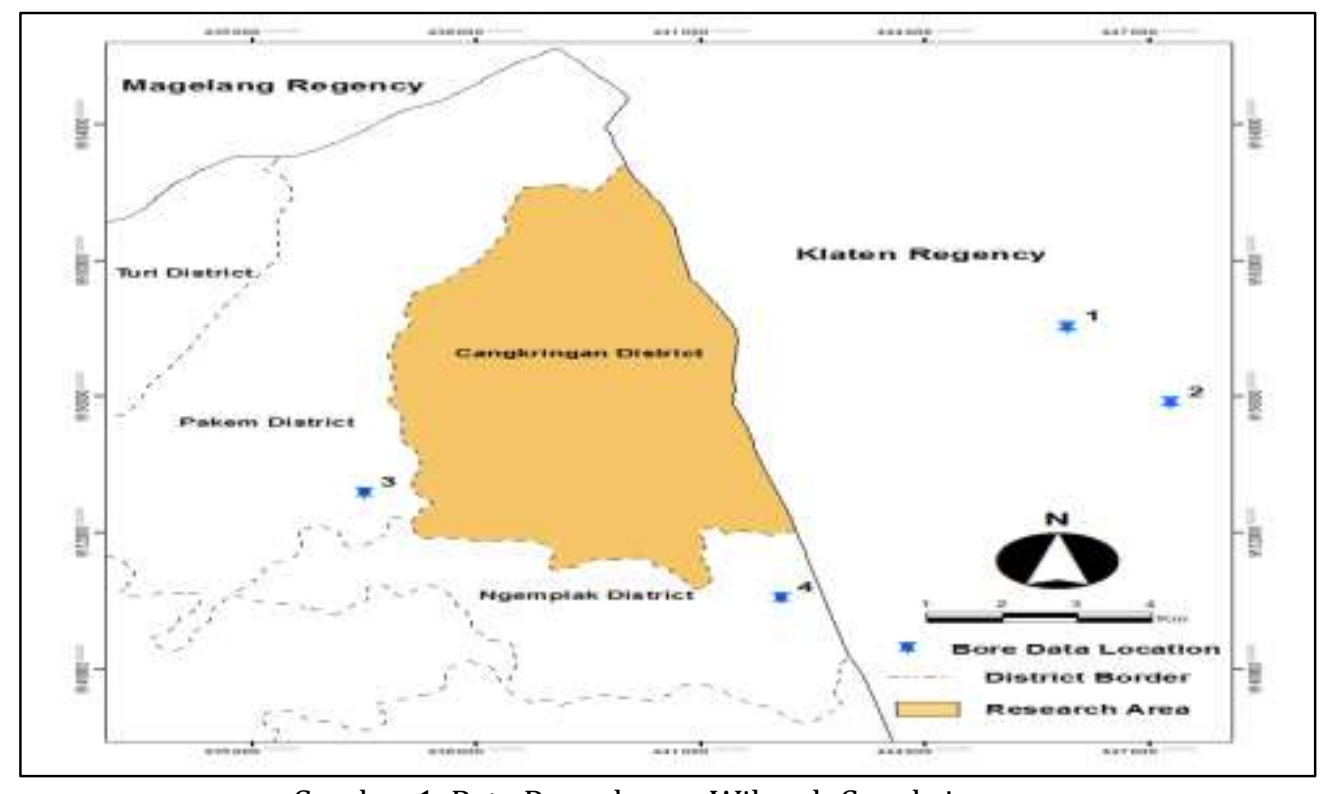

Gambar 1. Peta Pengeboran Wilayah Cangkrinagan

Sumber: (Riasasi \& Sejati, 2019)

Adapun komposisi dan ketebalan yang diperoleh dari hasil pengeboran di wilayah Kabupaten Cangkringan dapat dilihat pada tabel 1 sebagai berikut:

Table 1. Komposisi dan Ketebalan Lapisan Material di Lokasi Pengeboran.

\begin{tabular}{|c|c|c|c|}
\hline No & Location & Material & Thickness \\
\hline \multirow{8}{*}{1.} & \multirow{8}{*}{ Tangkil, Klaten [13] } & Soil & 5 \\
\hline & & Soil Mixed with Volcanic Breccia & 23 \\
\hline & & Rough Sand & 4 \\
\hline & & Volcanic Breccia and Frozen Sand & 32 \\
\hline & & Rough and Medium Sand & 7 \\
\hline & & Volcanic Breccia and Frozen Lava & 2 \\
\hline & & Rough and Medium Sand & 56 \\
\hline & & Volcanic Breccia & 31 \\
\hline
\end{tabular}




\begin{tabular}{lllr}
\hline \multirow{2}{*}{ 2. } & & Sgemplak, Klaten & 2.5 \\
& {$[13]$} & Volcanic Breccia & 17.5 \\
& & Sandstone & 20 \\
& & Volcanic Breccia and Frozen Lava & 9 \\
& & Rough and Medium Sand & 51 \\
& & Rough and Medium Sand & 50 \\
3. & Pakembinangun, & Soil & 1.5 \\
& Sleman [5] & Crushed and Fine Gravel & 4 \\
& & Rough and Fine Sand & 2.5 \\
& & Fine Gravel & 13 \\
& & Andesite & 1.5 \\
4. & Kanthungan, Sleman & 22.5 \\
& [5] & Soil & 5 \\
& & Meugh and Medium Sand & 8 \\
& & Claystone & 13 \\
& & Medium and Fine Sand & 14 \\
\end{tabular}

Sumber: (Riasasi \& Sejati, 2019)

Selain itu, wilayah ini juga memiliki curah hujan yang tinggi (Sutikno et al., 2007) dengan rata-rata $2.339 \mathrm{~mm}$ / tahun sampai dengan $2.753 \mathrm{~mm} /$ tahun (Permatasari \& Sejati, 2018; Sadewa Purba Sejati, 2013) dengan tipe iklim atau sedang. Sedangkan dari aspek geomorfologi kawasan ini termasuk dalam satuan bentuk lahan yang berasal dari proses vulkanik (Sadewa Purba Sejati, 2013). Atas dasar kondisi alamiah tersebut, wilayah Cangkringan dapat digolongkan sebagai daerah resapan air primer yang berfungsi sebagai sumber air.

Berdasarkan kondisi geografis tersebut, tim menilai perlu adanya penguatan pengetahuan tentang pentingnya kawasan air primer yang perlu dilestarikan sebagai bagian dari agenda pembangunan berkelanjutan sekaligus sebagai perwujudan dari amanah Tridharma Perguruan Tinggi, yaitu pengabdian kepada masyarakat, utamanya sumbangsih dosen dalam menyebarluaskan ilmu pengetahuan kepada masyarakat. Pengetahuan pembangunan berkelanjutan yang berkaitan dengan masalah air penting untuk diperkenalkan dan disebarluaskan kepada siswa sekolah dasar sebagai upaya menanamkan pengetahuan dan kesadaran lingkungan sebagai dasar untuk membentuk kepedulian lingkungan sejak dini dengan menggunakan media cerita bergambar kepada siswa. Cerita bergambar digunakan sebagai media pembelajaran karena dinilai mampu meningkatkan pemahaman siswa terhadap substansi pembelajaran dan sekaligus mengilustrasikan kata-kata yang dibawa oleh suatu cerita (Akbar \& Tarman, 2018; Alpiyah, Ambarita, \& Pargito, 2021; Hapsari, 2017; Restanto, 2016; S.P. Sejati et al., 2021; Triacca, 2017).

\section{METODE}

Kegiatan pengabdian masyarakat dilaksanakan dengan empat tahap yang terdiri dari, 1) analisis geografis terhadap situasi dan lingkungan serta telaah literatur, 2) wawancara mengenai kebutuhan mitra pengabdian tentang metode penguatan partisipasi terhadap agenda pembangunan berkelanjutan yang relevan bagi siswa sekolah dasar, 3) pelaksanaan kegiatan dalam bentuk pembelajaran di kelas menggunakan media cerita bergambar, dan 4) tahap evaluasi yang bertujuan untuk mengukur perubahan tingkat pengetahuan para siswa yang mengikuti kegiatan sebelum dan sesudah dilaksanakan kegiatan. Adapun alur pelaksanaan kegiatan pengabdian masyarakat ini dapat dilihat pada bagan berikut: 
Tinjauan literatur tentang pembangunan berkelanjutan dan analisis kondisi geografis wilayah Cangkringan

Wawancara dan analisis kebutuhan mitra sekaligus diskusi mengenai media penguatan yang relevan bagi siswa sekolah dasar

Penyajian materi kegiatan:

1. Pengantar video tentang air dan pembangunan berkelnajutan;

2. Penyajian materi pentingnya Kawasan resapan air melalui media cerita bergambar;

Evaluasi hasil kegiatan dan umpan balik mitra pengabdian masyarakat.

Gambar 2. Bagan Alur Pelaksanaan Kegiatan

\section{HASIL DAN PEMBAHASAN}

Kegiatan pengabdian masyarakat ini diikuti oleh 25 siswa sekolah dasar kelas 5 yang didampingi oleh para guru. Secara umum, partisipan telah belajar tentang pengetahuan lingkungan, tetapi sebagian belum mengetahui tentang kondisi alamiah wilayah mereka sebagai kawasan resapan air primer dan pembangunan berkelanjutan serta belum mengetahui jika kawasan sekitar mengalami kerusakan akan berpotensi terhadap pengurangan kuantitas air bersih.

Dalam melaksanakan kegiatan ini, tim pengabdian masyarakat menyajikan materi tentang pembangunan berkelanjutan menggunakan cerita bergambar yang di dalamnya memuat tiga aspek mendasar. Pertama, berinteraksi kepada para siswa tentang airtanah dalam bentuk tanya jawab dan penyajian video tentang pembangunan berkelanjutan. Kedua, memberikan ilustrasi kepada para siswa tentang resiko yang dihadapi jika wilayah resapan air mengalami kerusakan. Ketiga, memberikan contoh kepada para siswa tentang langkah-langkah sederhana yang dapat dilakukan dalam kegiatan sehari-hari belajar untuk menerapkan konsep pembangunan berkelanjutan dan cara memelihara wilayah resapan airtanah. Adapun media yang digunakan sebagai materi pembelajaran disajikan pada Gambar 3 sebagai berikut: 


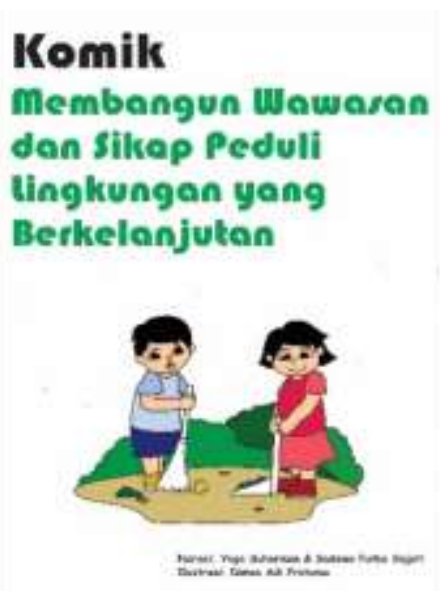

Sampul

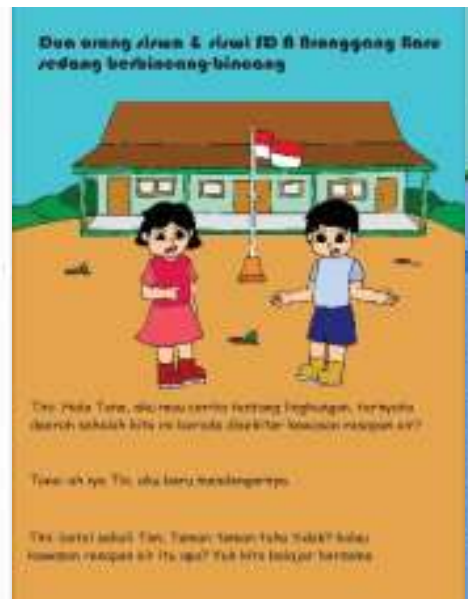

Isi halaman 2

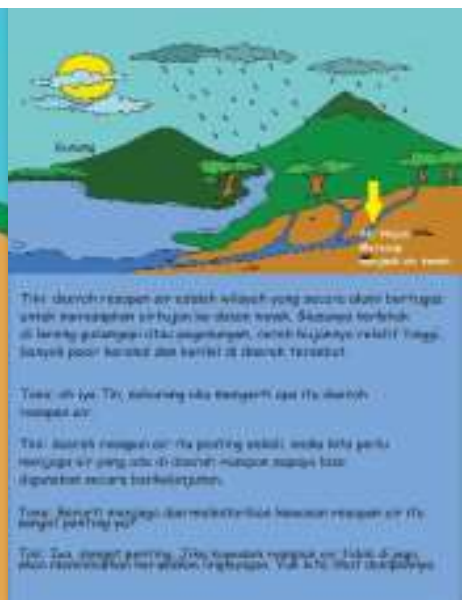

Isi halaman 3

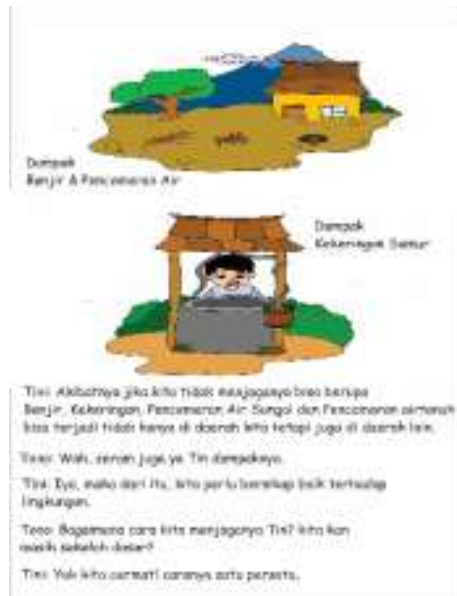

Isi halaman 4

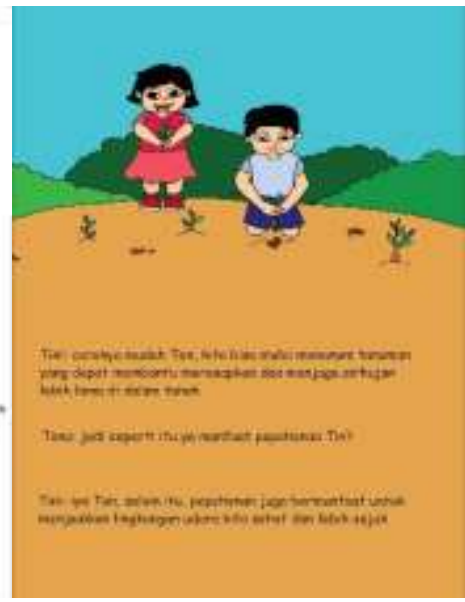

Isi halaman 5

Gambar 3. Media Cerita Bergambar

Adapun untuk mengukur hasil dari pengabdian masyarakat ini, tim (penulis) melakukan evaluasi tentang seberapa besar tingkat perubahan pemahaman peserta dengan metode perbandingan antara sebelum dan sesudah dilaksanakan kegiatan. Evaluasi dilakukan dengan mengajukan pertanyaan-pertanyaan tertulis kepada para siswa yang hadir dalam kegiatan pengabdian sebagai berikut:

1) Apakah sebelumnya kamu telah mengetahui tema tentang pembangunan berkelanjutan?;

2) Apakah sebelumnya kamu mengetahui tentang kawasan resapan air primer?;

3) Apakah kamu mengetahui manfaat/kegunaan wilayah resapan air primer dan airtanah sesudah kegiatan dilaksanakan?;

4) Apakah kamu mengetahui dampak buruk jika daerah resapan airtanah mengalami kerusakan?; dan

5) Apakah kamu mengetahui cara dan sikap sederhana yang diperlukan untuk memelihara daerah resapan airtanah sesudah kegiatan dilaksanakan?

Tingkat pemahaman siswa yang hadir dalam kegiatan diukur berdasarkan kriteria kualitatif, yaitu apabila siswa dapat menjawab pertanyaan nomor 3, 4, dan 5, maka dinyatakan terdapat perubahan tingkat pemahaman. Sedangkan, jika peserta didik hanya dapat menjawab 
antara satu atau dua dari pertanyaan nomor 3, 4, dan 5, maka para siswa dinyatakan belum memahami tema kegiatan pengabdian masyarakat. Adapun rincian respon peserta terhadap pertanyaan yang diberikan oleh tim dapat dilihat pada tabel 2 sebagai berikut:

Tabel 2. Evaluasi dan Respon Peserta terhadap Materi Pengabdian

\begin{tabular}{cllllllc}
\hline No & Partisipan & P 1 & P2 & P 3 & P 4 & P 5 & Kriteria \\
\hline 1. & Siswa/i 1 & x & x & $\checkmark$ & $\checkmark$ & $\checkmark$ & Memahami \\
2. & Siswa/i 2 & x & x & $\checkmark$ & $\checkmark$ & $\checkmark$ & Memahami \\
3. & Siswa/i 3 & x & x & $\checkmark$ & $\checkmark$ & $\checkmark$ & Memahami \\
4. & Siswa/i 4 & x & x & $\checkmark$ & $\checkmark$ & $\checkmark$ & Memahami \\
5. & Siswa/i 5 & x & x & $\checkmark$ & $\checkmark$ & $\checkmark$ & Memahami \\
6. & Siswa/i 6 & x & x & x & $\checkmark$ & $\checkmark$ & Belum Memahami \\
7. & Siswa/i 7 & x & x & $\checkmark$ & $\checkmark$ & $\checkmark$ & Memahami \\
8. & Siswa/i 8 & x & x & $\checkmark$ & $\checkmark$ & $\checkmark$ & Memahami \\
9. & Siswa/i 9 & x & x & $\checkmark$ & $\checkmark$ & $\checkmark$ & Memahami \\
10. & Siswa/i 10 & x & x & $\checkmark$ & $\checkmark$ & $\checkmark$ & Memahami \\
11. & Siswa/i 11 & x & x & $\checkmark$ & $\checkmark$ & $\checkmark$ & Memahami \\
12. & Siswa/i 12 & x & x & x & $\checkmark$ & x & Belum Memahami \\
13. & Siswa/i 13 & x & x & $\checkmark$ & $\checkmark$ & $\checkmark$ & Memahami \\
14. & Siswa/i 14 & x & x & $\checkmark$ & $\checkmark$ & $\checkmark$ & Memahami \\
15. & Siswa/i 15 & x & x & x & $\checkmark$ & x & Belum Memahami \\
16. & Siswa/i 16 & x & x & $\checkmark$ & $\checkmark$ & $\checkmark$ & Memahami \\
17. & Siswa/i 17 & x & x & $\checkmark$ & $\checkmark$ & $\checkmark$ & Memahami \\
18. & Siswa/i 18 & x & x & $\checkmark$ & $\checkmark$ & $\checkmark$ & Memahami \\
19. & Siswa/i 19 & x & x & x & x & x & Belum Memahami \\
20. & Siswa/i 20 & x & x & $\checkmark$ & $\checkmark$ & $\checkmark$ & Memahami \\
21. & Siswa/i 21 & x & x & $\checkmark$ & $\checkmark$ & $\checkmark$ & Memahami \\
22. & Siswa/i 22 & x & x & $\checkmark$ & $\checkmark$ & $\checkmark$ & Memahami \\
23. & Siswa/i 23 & x & x & $\checkmark$ & $\checkmark$ & x & Belum Memahami \\
24. & Siswa/i 24 & x & x & $\checkmark$ & $\checkmark$ & $\checkmark$ & Memahami \\
25. & Siswa/i 25 & x & x & $\checkmark$ & $\checkmark$ & $\checkmark$ & Memahami \\
\hline
\end{tabular}

Sumber: diolah dari data primer (2019)

Secara kuantitatif, respon siswa setelah kegiatan menunjukkan bahwa 80\% dari dari 25 peserta menjadi lebih mengetahui materi dan $20 \%$ sisanya belum memahami materi. Angka ini menunjukkan adanya perubahan tingkat pemahaman para siswa/i tentang materi yang disajikan dalam kegiatan pengabdian masyarakat. Adapun Prosentase hasil tingkat pemahaman siswa terhadap materi kegiatan dapat dilihat pada gambar 4 sebagai berikut:

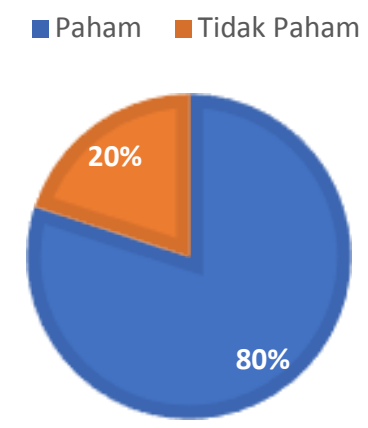

Gambar 4. Prosentase perubahan tingkat pemahaman siswa/i terhadap materi kegiatan Sumber: data primer diolah (2019). 
Salah satu tolak ukur keberhasilan pelaksanaan kegiatan ini adalah umpan balik dari mitra pengabdian masyarakat. Untuk memperoleh umpan balik dari mitra pengabdian, pada akhir pelaksanaan kegiatan, tim melakukan upaya memperoleh umpan balik mitra terhadap kegiatan yang dilaksanakan. Berdasarkan hasil wawancara tim dengan kepala sekolah SD Negeri Bronggang Baru diperoleh hasil bahwa cerita bergambar yang digunakan sebagai media pembelajaran untuk peningkatan pengetahuan siswa/i tentang pembangunan berkelanjutan dan airtanah dalam kegiatan pengabdian masyarakat sangat positif tidak hanya bagi para siswa, tetapi juga bagi para guru untuk berinovasi dalam mengembangkan media pembelajaran lainnya.

Respon mitra diringkas menjadi tiga bagian penting, yakni (a) media yang digunakan relevan dan memberikan daya tarik bagi para siswa/i sekolah dasar; (c) media cerita bergambar semacam ini dapat memberi manfaat positif bagi para guru untuk mengembangkan media sejenis untuk kebutuhan pembelajaran. Media cerita bergambar memberikan gambaran tentang kondisi lingkungan resapan air dan lebih mengetahui bagaimana cara-cara yang dapat dilakukan untuk mencegah potensi kerusakan lingkungan.

Adapun manfaat kegiatan yang diperoleh siswa dari media cerita bergambar antara lain: (1) sebagian besar siswa telah memahami kondisi geografis dan lingkungan sekitar sebagai kawasan resapan air primer; (2) peserta memperoleh pengetahuan tentang pembangunan berkelanjutan tentang pentingnya kelestarian airtanah bagi masyarakat dan lingkungan; (3) membentuk sikap hemat dalam menggunakan air sehari-hari; (4) membentuk sikap sadar mengenai bahaya sampah plastik bagi wilayah resapan airtanah; (5) memperoleh manfaat pengetahuan tentang pentingnya reboisasi.

\section{KESIMPULAN}

Berdasarkan uraian hasil kegiatan pengabdian masyarakat yang mengangkat judul "Peningkatan Pengetahuan Pembangunan Berkelanjutan Menggunakan Media Cerita Bergambar ditingkat Sekolah Dasar" diperoleh kesimpulan bahwa upaya untuk pengetahuan tentang air dan pembangunan berkelanjutan masih sangat diperlukan untuk disebarluaskan kepada masayarakat, termasuk komunitas sekolah dasar dalam berbagai bentuk yang relevan.

Media cerita bergambar yang digunakan dalam kegiatan ini perlu dikembangan sebagai bentuk inovasi yang dapat dimanfaatkan sebagai materi pembelajaran bagi siswa/siswi sekolah dasar agar lebih mudah dipahami. Kekuatan kapasitas kognitif dan sikap yang relevan dengan kebutuhan agenda pembangunan berkelanjutan menjadi modal dalam memelihara ekosistem dan meningkatkan sumber daya manusia Indonesia di masa mendatang. Dengan media cerita bergambar, para siswa dan siswi dapat lebih mudah menginternalisasi pengetahuan dan nilainilai positif yang terkandung di dalamnya dan dapat disebarluaskan kepada kerabat dan masyarakat sekitar.

\section{UCAPAN TERIMA KASIH}

Penulis mengucapkan terima kasih kepada Lembaga Pengabdian Masyarakat Universitas Amikom Yogyakarta yang telah memberikan dukungan baik secara kelembagaan atas terlaksananya kegiatan pengabdian kepada masyarakat ini.

\section{DAFTAR PUSTAKA}

Apriani, W., \& Trisep Haris, V. (2019). IbM Sosialisasi Penerapan Lubang Resapan Biopori Bagi Masyarakat di Lingkungan RW 06 Dan RW 18 Kelurahan Sidomulyo Barat Kota Pekanbaru. Dinamisia : Jurnal Pengabdian Kepada Masyarakat, 3(Juni), 149-155. https://doi.org/10.31849/dinamisia.v3i2.2908

Akbar, A. A., \& Tarman. (2018). Pengaruh Penggunaan Medi Gambar Terhadap Hasil Belajar 
Bahasa Indonesia pada Siswa Kelas IV Sekolah Dasar. Jurnal Riset Pendidikan Dasar, 1(April), $40-48$.

Alpiyah, Ambarita, A., \& Pargito. (2021). The development of environment-based picture storybooks to increase the fourth grade students' reading interest Research method. International Journal of Educational Studies in Social Sciences, 1(3), 118-120. https://doi.org/10.53402/ijesss.v1i3.24

Asdak, C. (2014). Hidrologi dan Pengelolaan Daerah Aliran Sungai. Yogyakarta: UGM Press

Dharoko, A. (2006). Model Arahan Pemanfaatan Lahan untuk Konservasi Sumberdaya Air di Kabupaten Sleman. Manusia Dan Lingkungan, 13(2), 90-99.

Ferranti, P. (2018). The United Nation's Sustainable Development Goals. Encyclopedia of Food Security and Sustainability, 1, 6-8. https://doi.org/10.1016/B978-0-12-812687-5.22063-7

Hapsari, M. I. (2017). Use of Picture and Method in Increasing Ability of Sunware Students. Journal of Elementary Education, 1(1), 91-108.

Hendrayana, H., \& Vicente, V. A. de S. (2013). Cadangan Airtanah Berdasarkan Geometri dan Konfigurasi Sistem Akuifer Cekungan Airtanah Yogyakarta-Sleman. Prosiding Seminar Nasional Kebumian Ke-6, 11-12.

Kodoatie, R. J. (2012). Tata Ruang Airtanah. Yogyakarta: Andi.

Mawardi, I. (2010). Kerusakan Daerah Aliran Sungai dan Penurunan Daya Dukung Sumberdaya Air di Pulau Jawa serta Upaya Penanganannyal. Jurnal Hidrosfer Indonesia 5(2), 1-11.

Pauw, J. B. de, Gericke, N., Olsson, D., \& Berglund, T. (2015). The Effectiveness of Education for Sustainable Development. Sustainability, 7(11), 15693-15717. https://doi.org/10.3390/su71115693.

Permatasari, A. L., \& Sejati, S. P. (2018). Pengujian Materi Mitigasi Bencana Erupsi Merapi dengan Pendekatan Spasial melalui Metode Visual dan Field Trip. Geomedia, 16(2), 89-96.

Restanto, M. (2016). The Use of Picture Book in Teaching Reading for Junior High School Students. Journal of English and Education, 4(2), 49-62.

Riasasi, W., \& Sejati, S. P. (2019). Potential of Groundwater to Supply Domestic Water Necessity in Evacuation Shelters of Merapi Volcano Eruption. IOP Conference Series: Earth and Environmental Science, 271(1). https://doi.org/10.1088/1755-1315/271/1/012014

Sejati, S.P., Rosaji, F. S. C., Permatasari, A. L., Nucifera, F., Suherningtyas, I. A., Kusnawi, ... Sekarsih, F. N. (2021). Teknologi Geospasial Sebagai Media Pembelajaran Geografi di Lingkungan Sekolah Tingkat Menengah. Geomedia:Majalah Ilmiah Dan Informasi Kegeografian, 19(1), 1525.

Sejati, Sadewa Purba. (2017). Karakteristik Sumber Daya Airtanah Dangkal Di Kecamatan Cangkringan Kabupaten Sleman Provinsi Daerah Istimewa Yogyakarta. Media Komunikasi Geografi, 18(2), 166-177.

Sejati, Sadewa Purba. (2013). Kajian Potensi Airtanah di Lereng Selatan Gunungapi Merapi untuk Mencukupi Kebutuhan Domestik pada Hunian Sementara. Universitas Gadjah Mada.

Setyowati, D.L., Suharini, E. (2014). DAS Garang Hulu: Tata Air, Erosi, dan Konservasi. Penerbit : Ombak. Yogyakarta: Ombak

Springett, D., \& Redclift, M. (2015). Handbook of Sustainable Development. In M. Redclift \& D. Springett (Eds.), Routledge International Handbook of Sustainable Development. London: Routledge.

Todd, D. K., \& Mays, L. W. (2005). Groundwater Hydrology Third Edition. New York: John Willey and Son Inc.

Triacca, S. (2017). Teaching and Learning with Pictures The Use of Photography in Primary Schools. MDPI, 1(952), 1-10. https://doi.org/10.3390/proceedings1090952.

United Nations. (2016). Water and Sanitation - United Nations Sustainable Development. Sustainable Development Goals. https://www.un.org/sustainabledevelopment/water-andsanitation/

Wahyuni, W., Arsyad, U., Bachtiar, B., \& Irfan, M. (2017). Identifikasi Daerah Resapan Air di Sub Daerah Aliran Sungai Malino Hulu Daerah Aliran Sungai Jeneberang Kabupaten Gowa. Jurnal Hutan Dan Masyarakat, 9(2), 93-104. https://doi.org/10.24259/jhm.v9i2.2891. 